\title{
STUDI ANALISIS KEKUATAN, DAYA TAHAN OTOT, DAN POWER ATLET BOLAVOLI PUTRI KOTA KEDIRI
}

\author{
Reo Prasetiyo Herpandika
}

\author{
Universitas Nusantara PGRI Kediri \\ E-mail: reoprasetiyo@unpkediri.ac.id \\ DOI: https://doi.org/10.36526/kejaora.v5i2.1066
}

\begin{abstract}
ABSTRAK
Tujuan penelitian ini untuk mengetahui kondisi kekuatan, daya tahan otot, dan power pada atlet bolavoli putri Kota Kediri. Dimana komponen kondisi fisik ini sangat dominan dalam permainan bolavoli. Jenis penelitian ini adalah deskriptif kuantitatif. Sampel penelitian adalah atlet bolavoli putri yang berjumlah 14 dengan kategori kelompok umur 15-19 tahun. Analisis data menggunakan statistik prosentase. Hasil penelitian menunjukkan bahwa kondisi kekuatan dalam kategori "baik" yaitu sebesar $43 \%$, daya tahan otot dengan kategori "baik sekali" dengan prosentase $36 \%$, sedangkan power dalam kategori "baik sekali" dengan prosentase $64 \%$. Berdasarkan hasil analisis data yang menunjukkan kategori dengan prosentase, maka dapat disimpulkan kondisi kekuatan, daya tahan otot, dan power atlet bolavoli putri Kota Kediri sudah termasuk dalam kategori "baik sekali". Artinya atlet yang didukung dengan kondisi fisik yang baik akan lebih mudah dalam mencapai target yaitu prestasi dalam olahraga.
\end{abstract}

Kata Kunci: Kekuatan, Daya Tahan Otot, Power, Bolavoli

\section{PENDAHULUAN}

Dalam kehidupan yang modern olahraga telah menjadi tuntutan dan kebutuhan hidup agar lebih sejahtera, olahraga semakin diperlukan oleh manusia dalam kehidupan yang semakin kompleks dan serba otomatis, manusia dapat mempertahankan eksistensinya terhindar dari berbagai gangguan atau difungsi sebagai akibat kekurangan gerak, olahraga yang dilakukan dengan tepat dan benar maka akan sangat bermanfaat bagi tubuh (Santoso, 2016)

Setiap manusia dalam melaksanakan aktivitas sehari-hari memerlukan kondisi kebugaran jasmani yang baik. Tingkat kebugaran jasmani seseorang akan berpengaruh terhadap kesiapan fisik maupun pikiran untuk dapat menerima beban kerja (Setyaningsih \& Yuliandi, 2019). Dalam setiap cabang olahraga memerlukan kesiapan kondisi fisik dan penguasaan teknik yang tinggi, disamping itu faktor mental dan emosional sebagai bagian dari sistem faktor penentuan keberhasilan (Pratama, 2016).

Melalui olahraga seorang dapat kesempatan luas untuk mengembangkan kemampuan, mendapatkan pengakuan, dan popularitas, pengalaman bertanding, kegembiraan, dan kepuasan. Hakikat olahraga merupakan kegiatan fisik yang mengandung sifat permainan dan berisi perjuangan melawan diri sendiri, melawan orang lain, atau konfrontasi dengan alam. Kegiatan olahraga meliputi gaya pertandingan, maka gaya itu harus dilaksanakan dengan semangat dan jiwa sportif

Kondisi fisik sangat berperan dalam semua aktivitas secara umun dan khususnya di bidang olahraga. Tanpa kondisi fisik yang baik maka kita akan merasa terhambat dalam melaksanakan sebuat aktivitas apalagi berolahraga. Olahraga merupakan kegiatan yang sangat dibutuhkan oleh setiap orang untuk mempertahankan kesehatan dan kebugaran fisik yang dimilikinya. Selain memberikan kesehatan dan kebugaran fisik, aktivitas olahraga dapat dijadikan sebagai ajang kompetensi untuk berpacu dalam pencapaian sebuah prestasi, baik secara individu maupun kelompok (Maliki et al., 2017). 
Olahraga bolavoli merupakan permainan tim yang membutuhkan kondisi fisik dalam permainannya. Dalam bolavoli terdapat berbagai teknik dasar yang harus dikuasai oleh atletnya seperti service, smash, blok, dan passing. Sesuai dari ide permainan bolavoli, agar dapat bermain bolavoli dengan baik, seorang pemain harus dapat menguasai teknik dasar permainan bolavoli. Teknik dasar permainan bolavoli harus benar-benar dikuasai terlebih dahulu agar dapat mengembangkan mutu prestasi permainan bolavoli (Prasetyo \& Umar, 2020). Seorang atlet yang menghadapi pertandingan harus memiliki persiapan, baik fisik maupun mental (Setiabudi \& Santoso, 2020). Pencapaian prestasi dalam bolavoli tentunya sangat membutuhkan kondisi fisik seperti kecepatan, kekuatan dan power.

Para atlet harus melakukan latihanlatihan yang telah diprogramkan oleh pelatih agar dapat mencapai target yang telah ditentukan sesuai dengan program latihan itu sendiri. Karena tanpa latihan yang teratur, terukur, dan kontinyu seorang atlet tidak akan bisa berprestasi secara maksimal (Silpina et al., 2020).

Dengan adanya penelitian ini maka dapat digambarkan bagaimana kondisi fisik atlet bolavoli putri Kota Kediri, sehingga menjadi acuan utama seorang pelatih dalam meningkatkan dan memertahankan kondisi fisik atletnya.

\section{METODE}

Penelitian ini termasuk penelitian deskriptif, dimana penelitian yang bersifat menggambarkan suatu fenomena, peristiwa, gejala, menggunakan data kuantitatif maupun kualitatif (Sugiyono, 2014). Sampel dalam penelitian ini adalah atlet bolavoli putri Kota Kediri usia 15-19 tahun yang berjumlah 14 atlet. Intsrumen penelitian menggunakan tes dan pengukuran yaitu tes kekuatan, daya tahan otot, dan tes power. Analisis data menggnakan perhitungan prosentase.

\section{HASIL DAN PEMBAHASAN}

Berdasarkan hasil analisis data kekuatan, daya tahan otot, dan power, maka dapat dipaparkan dalam bentuk tabel di bawah ini:

Tabel 1. Deskripsi Kekuatan Peras Tangan dan Otot Tungkai

\begin{tabular}{lcc}
\hline Kategori & Peras Tangan & Otot Tungkai \\
\hline Baik Sekali & $0 \%$ & $36 \%$ \\
\hline Baik & $50 \%$ & $36 \%$ \\
\hline Sedang & $50 \%$ & $21 \%$ \\
\hline Kurang & $0 \%$ & $7 \%$ \\
\hline Kurang Sekali & $0 \%$ & $0 \%$ \\
\hline
\end{tabular}

Deskripsi pada tabel 1 di atas menunjukkan kategori kekuatan peras tangan "baik" dengan prosentase $50 \%$ dan kekuatan otot tungkai kategori "baik sekali" dengan prosentase $36 \%$. Hasil analisis data di atas juga dapat ditampilkan dalam bentuk grafik di bawah ini:

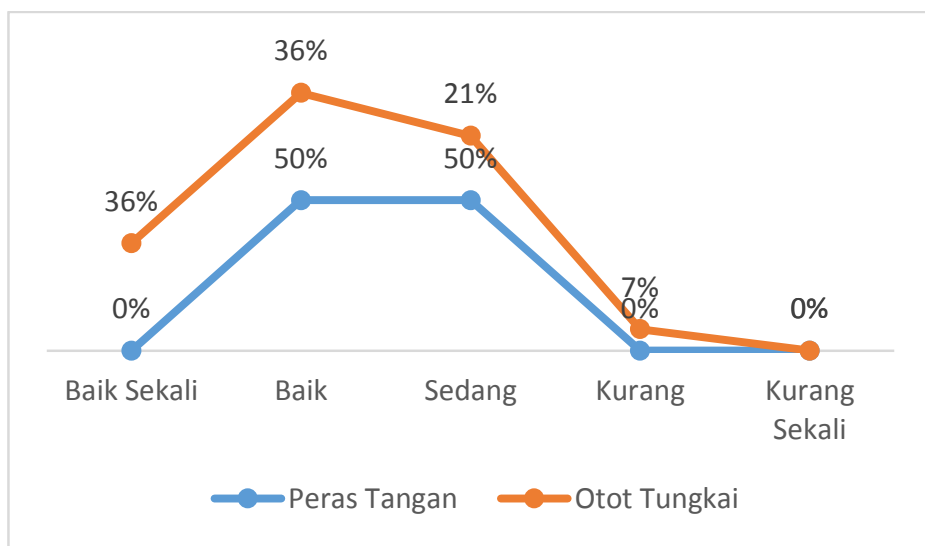

Grafik 1. Deskripsi Kekuatan Peras Tangan dan Otot Tungkai 
Jurnal Kejaora: Jurnal Kesehatan Jasmani dan Olah Raga

ISSN: 2541-5042 (Online)

ISSN: 2503-2976 (Print)

Volume 5 Nomor 2, Edisi November 2020

Tabel 2. Deskripsi Data Kekuatan

\begin{tabular}{lc}
\hline \multicolumn{1}{c}{ Kategori } & Kekuatan \\
\hline Baik Sekali & $18 \%$ \\
\hline Baik & $43 \%$ \\
\hline Sedang & $36 \%$ \\
\hline Kurang & $4 \%$ \\
\hline Kurang Sekali & $0 \%$ \\
\hline
\end{tabular}

Berdasarkan tabel 2 di atas maka dapat dijelaskan bahwa kekuatan dalam kategori "baik" dengan tingkat prosetase $43 \%$. Data kekuatan juga dapat ditampilkan dengan grafik di bawah ini:

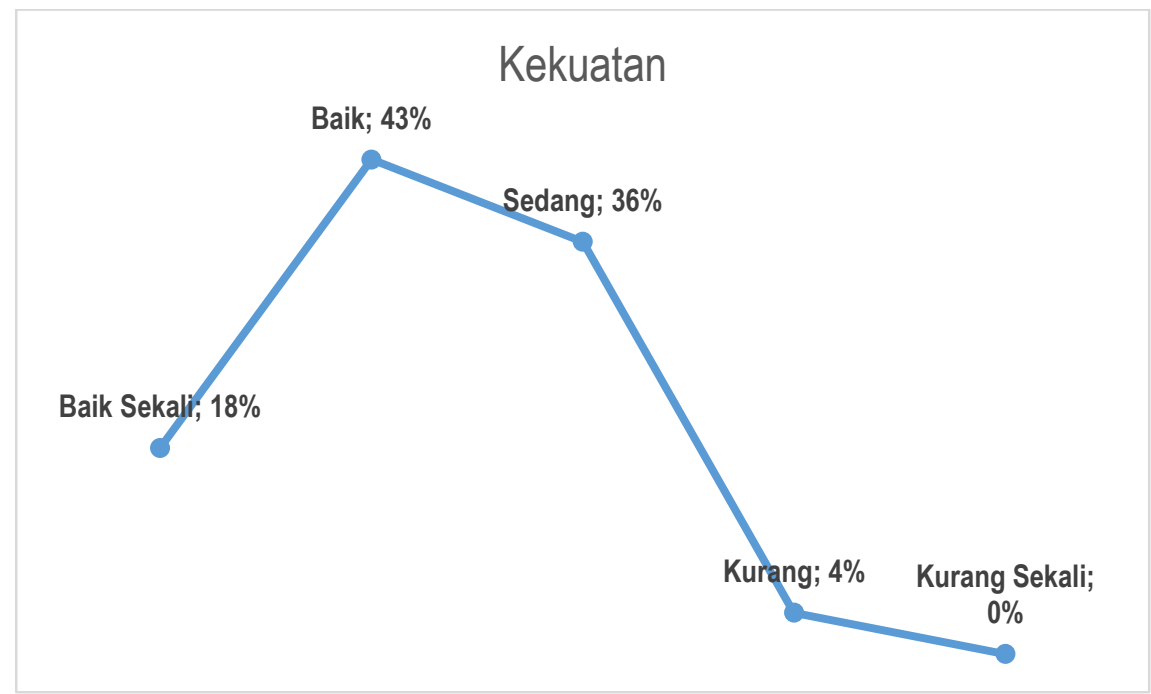

Grafik 2. Deskripsi Data Kekuatan

Tabel 3. Deskripsi Daya Tahan Otot Perut dan

\section{Lengan}

\begin{tabular}{lll}
\hline Kategori & Otot Perut & Otot Lengan \\
\hline Baik Sekali & $28,6 \%$ & $42,9 \%$ \\
\hline Baik & $0,0 \%$ & $28,6 \%$ \\
\hline Sedang & $35,7 \%$ & $28,6 \%$ \\
\hline Kurang & $21,4 \%$ & $0,0 \%$ \\
\hline Kurang Sekali & $14,3 \%$ & $0,0 \%$ \\
\hline
\end{tabular}

Berdasarkan tabel 3 di atas, kategori daya tahan otot perut dalam kategori "sedang", dengan prosentase $35,7 \%$. Sedangkan daya tahan otot lengan dalam kategori "baik sekali" dengan prosentase $42,9 \%$.

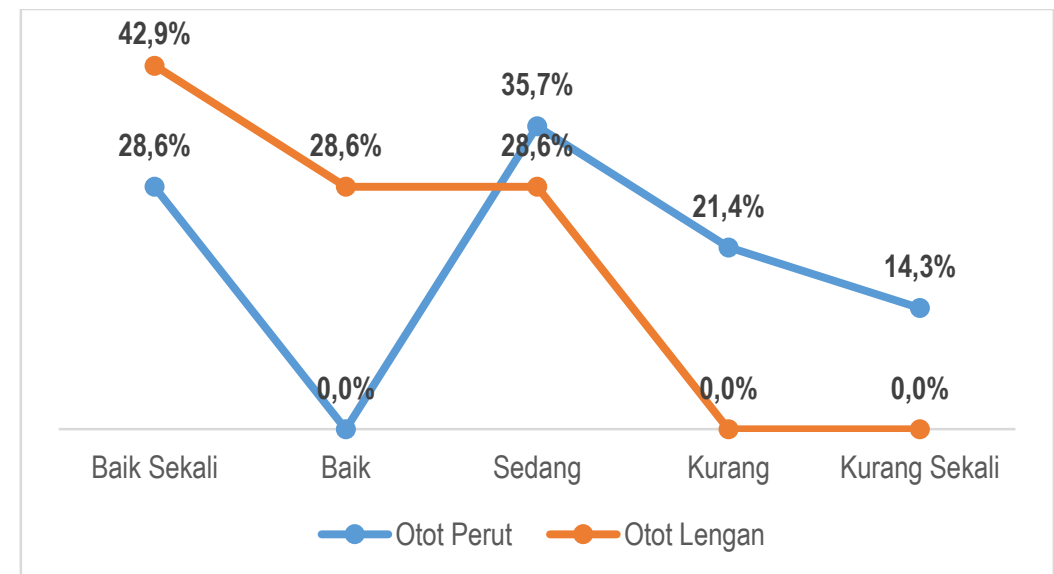

Grafik 3. Daya Tahan Otot Perut dan Otot Lengan 
Jurnal Kejaora: Jurnal Kesehatan Jasmani dan Olah Raga

ISSN: 2541-5042 (Online)

ISSN: 2503-2976 (Print)

Volume 5 Nomor 2, Edisi November 2020

Tabel 4. Daya Tahan Otot

\begin{tabular}{ll}
\hline Kategori & Daya Tahan Otot \\
\hline Baik Sekali & $36 \%$ \\
\hline Baik & $14 \%$ \\
\hline Sedang & $32 \%$ \\
\hline Kurang & $11 \%$ \\
\hline Kurang Sekali & $7 \%$ \\
\hline
\end{tabular}

Berdasarkan tabel 4 di atas dapat dideskripsikan bahwa daya tahan otot atlet bolavoli putri Kota Kediri dalam kategori "baik sekali" dengan prosetase 36\%. Data juga dapat ditampilkan dalam grafik di bawah ini:

\section{Daya Tahan Otot}

Baik Sekali; $36 \%$

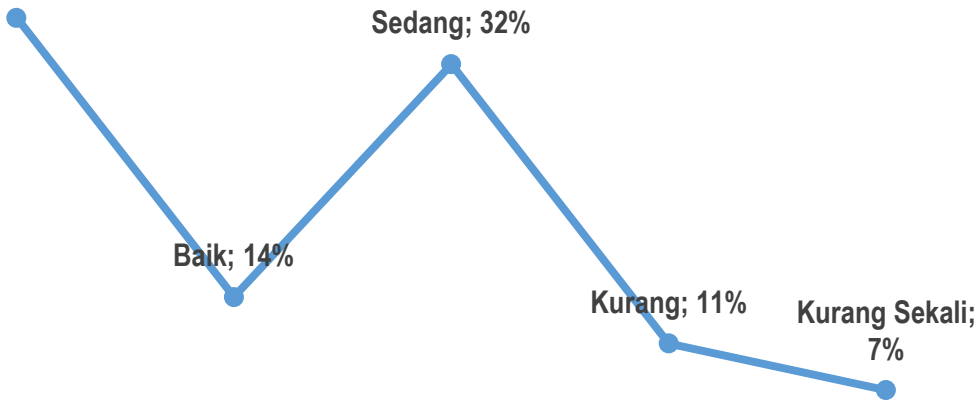

Grafik 4. Daya Tahan Otot

Tabel 5. Deskripsi Power

\begin{tabular}{ll}
\hline Kategori & Power \\
\hline Baik Sekali & $64 \%$ \\
\hline Baik & $36 \%$ \\
\hline Sedang & $0 \%$ \\
\hline Kurang & $0 \%$ \\
\hline Kurang Sekali & $0 \%$ \\
\hline
\end{tabular}

Berdasarkan tabel 5 di atas dapat dideskripsikan bahwa power atlet bolavoli putri Kota Kediri dalam kategori "baik sekali", dengan prosentase $64 \%$. Data juga dapat ditampilkan dalam grafik di bawah ini:

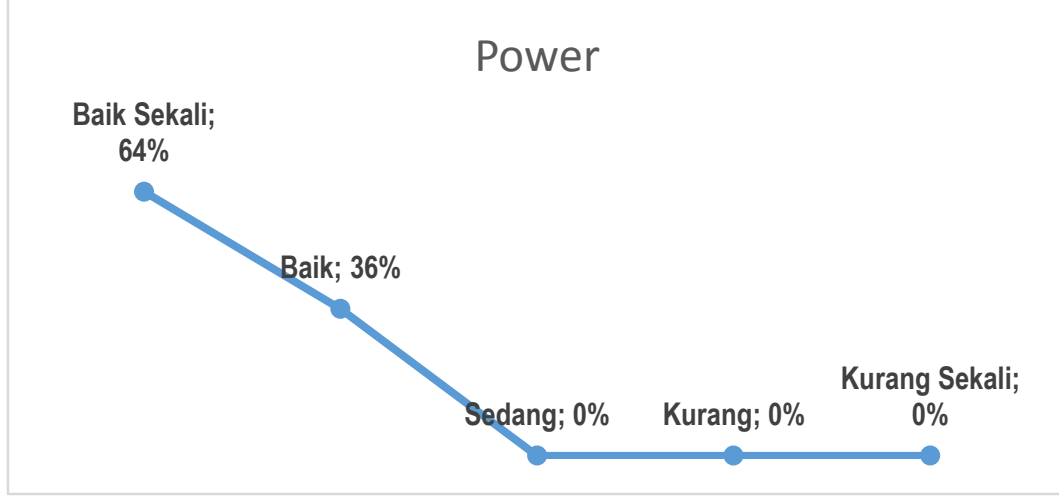

Grafik 5. Power

Dalam penelitian ini ditemukan bahwa kondisi kekuatan peras tangan dan otot tugkai atlet bolavoli putri Kota Kediri dalam kategori baik. Kekuatan merupakan salah satu 
Jurnal Kejaora: Jurnal Kesehatan Jasmani dan Olah Raga

ISSN: 2541-5042 (Online)

ISSN: 2503-2976 (Print)

Volume 5 Nomor 2, Edisi November 2020

indikator yang mempunnnyai peranan penting dalam permainan bolavoli. Kekuatan peras tangan sangat berkotribusi pada pengumpan atau setter saat melakukan umpan. Hal ini didukung dengan hasil penelitian bahwa kekuatan peras tangan kurang memberikan kontribusi terhadap keterampilan servis atas (Yanti, 2019). Sedangkan pada kekuatan otot tungkai yang sangat mendukung dalam gerakan meloncat pada permainan bolavoli seperti smash dan blok.

Begitu juga daya tahan otot lengan sangat mendukung dalam teknik permainan bolavoli. Kekuatan otot lengan berkontribusi terhadap keterampilan smash bola voli, maka kekuatan otot lengan dapat dijadikan sebagai alat untuk memprediksi keterampilan smash bola voli (Supriyanto \& Martiani, 2019). Dimana smash adalah suatu tindakan memukul bola dengan keras menggunakan teknik tertentu agar bola bisa memasuki lapangan lawan dengan harapan tidak dapat dibendung oleh tim regu lain sebagai lawan dalam permainan, sehingga bisa meraih angka.

Temuan lain dalam penelitian ini yaitu power atau daya ledak atlet bolavoli putri Kota Kediri dalam kategori sagat baik. Daya ledak berguna saat melakukan gerakan cepat yang disertai dengan kekuatan seperti meloncat saat melakukan smash atau blok. Karena pada dasarnya, siapa yang paling tinggi raihan di atas net maka akan memenangkan duel di udara saat smash dan blok. Sehingga secara tidak langsung angka sangat mudah diraih dalam permainan.

Dalam olahraga bolavoli khususnya pada teknik ketepatan smash, Daya Ledak otot tungkai merupakan salah satu komponen kondisi fisik yang sangat diperlukan dalam melakukan smash. Tanpa memiliki daya ledak otot tungkai yang baik akan mempengaruhi hasil smash yang dilakukan serta mempengaruhi ketepatan smash sehingga akan sulit untuk meraih prestasi khususnya dalam cabang olahraga bolavoli. Daya ledak otot tungkai yang dimaksud disini adalah daya ledak otot kaki yang digunakan untuk meloncat akan mempermudah melihat daerah lawan pada saat melakukan smash dalam permainan bolavoli. Daya ledak

tersebut diperlukan untuk meloncat saat melakukan smash (Tifali \& Padli, 2020).

Artinya komponen kekuatan, daya tahan otot, dan power merupakan komponen kondisi fisik yang mutlak dilatih pada atlet dalam meningkatkan teknik dalam permainan bolavoli.

\section{KESIMPULAN}

Dalam hasil analisis ini ditemukan bahwa kekuatan atlet bolavoli putri Kota Kediri dalam kategori baik, daya tahan otot dalam kategori baik sekali dan power dalam kategori baik sekali. Pemain bolavoli yang memiliki kondisi baik pada ketiga komponen kondisi fisik ini tentunya akan dengan sangat mudah dalam melakukan gerakan teknik dalam permainan bolavoli. Maka dari itu disarankan untuk terus menjaga kondisi agar tetap stabil dengan program latihan yang cepat dan tepat oleh seorang pelatih. Dalam penelitian ini diharapkan dapat bermafaat bagi para atlet dalam mejaga dan mempertahanka kodisi fisiknnya. Untuk penelitian selanjutnya dapat mengembangkan dan menganalisis lebih mendalam terkait kodisi fisik yang sangat dibutuhkan sesuai dengan karakter permainan bolavoli

\section{DAFTAR PUSTAKA}

Maliki, O., Hadi, H., \& Royana, I. F. (2017). Analisis Kondisi Fisik Pemain Sepakbola Klub PERSEPU UPGRIS Tahun 2016. Jendela Olahraga, 2(2), 1-8.

Prasetyo, W. E., \& Umar. (2020). Studi Kondisi Fisik Bolavoli. Jurnal Patriot, 2(2), S- 102.

Pratama, H. G. (2016). Pengaruh Power Tungkai Dan Kekuatan Lengan Terhadap Kemampuan Standing Jump Shoot Dan Quick Jump Shoot. Jurnal Pendidikan Dewantara, 2(2), 127-140.

Santoso, D. A. (2016). Analisis Tingkat Kebugaran Jasmani Atlet Bolavoli Putri Universitas Pgri Banyuwangi. Kejaora, 1(1), 37-46.

Setiabudi, M. A., \& Santoso, D. A. (2020). Tingkat kecemasan (Anxiety) Dalam Olahraga Berbasis Perbedaan Etnis 
Jurnal Kejaora: Jurnal Kesehatan Jasmani dan Olah Raga

ISSN: 2541-5042 (Online)

ISSN: 2503-2976 (Print)

Volume 5 Nomor 2, Edisi November 2020

(Suku Osing, Jawa, Dan Madura). Jurnal Altius: Jurnal Ilmu Olahraga Dan Kesehatan, 9(1), 1-8.

Setyaningsih, P., \& Yuliandi, R. (2019). Perbandingan Tingkat Kebugaran Siswa Yang Mengikuti Dan Tidak Mengikuti Kegiatan Sanggar Tari. Altius: Jurnal IImu Olahraga Dan Kesehatan, 8(1), 1-8. https://doi.org/10.36706/altius.v8i1.82 38

Silpina, P., Sugihartono, T., \& Sutisyana, A. (2020). Analisis Kondisi Fisik Atlet Club Bola Voli Putri Di Kota Bengkulu Tahun 2020. SPORT GYMNASTICS: Jurnal IImiah Pendidikan Jasmani, 1(1), 31-36. https://doi.org/10.33369/gymnastics.v $1 \mathrm{i} 1.12523$

Sugiyono. (2014). Cara Mudah Menyusun: Sripsi, Tesis, dan Disertasi (2nd ed.). Bandung:Alfabeta.

Supriyanto, S., \& Martiani, M. (2019). Kontribusi Kekuatan Otot Lengan terhadap Keterampilan Smash dalam Permainan Bola Voli. Gelanggang Olahraga: Jurnal Pendidikan Jasmani Dan Olahraga (JPJO), 3(1), 74-80. https://doi.org/10.31539/jpjo.v3i1.829

Tifali, U. R., \& Padli. (2020). Kontribusi Daya Ledak Otot Tungkai Dan Daya Ledak Otot Lengan Terhadap Ketepatan Smash Atlet Bolavoli Putra Klub Semen Padang. Jurnal Patriot, 2(2), 565-575.

Yanti, N. (2019). Kontribusi Kekuatan Peras Tangan Terhadap Hasil Servis Atas Pada Bola Voli. Jurnal IImu Keolahragaan, II(2), 39-45. 